\title{
Machine Tool Accuracy DMG MORI DMU 50 measuring by system Ballbar QC20-W
}

\author{
Radim Liška' , Dagmar Šoková', Robert Čep ${ }^{1 *}$, Lenka Čepová' and Jiří Kratochvil' ${ }^{1}$ \\ VŠB-Technical university of Ostrava, Faculty of Mechanical Engineering, 17. Listopadu 2172/15, 70800 0strava, Czech Republic
}

\begin{abstract}
This article deals with the measurement and evaluation of the circularity of the machine DMG MORI - DMU 50 using the measuring system Ballbar QC20-W, which can measure the circularity of the machine using circular interpolation. Furthermore, the system can evaluate machine errors or measurement errors. This can prevent a number of problems, such as financial losses, compliance with the required accuracy and adherence to order deadlines. All three planes of the machine tool were measured - XY, YZ and ZX. In each plane, accuracy (roundness deviations) was measured at three values of feed rate 1000, 1500 and 2000 m.min-1. Each measurement was evaluated and in the end the dependence in individual planes on the feed rate is given.
\end{abstract}

Keywords: machine tool; accuracy; roundness deviation; measuring; Ballbar QC20-W

\section{Introduction}

We live in a time when the emphasis is primarily on price, speed, accuracy and quality. Thanks to this, CNC machines have their inseparable place in mechanical engineering. Their use can be seen in the automotive, aerospace, rubber, and other industries, which have a great impact on our daily lives [1].

However, they also have a place in the dental industry, where they are used to produce, for example, tooth crowns, but also entire dentures. In the medical industry, it is used to produce surgical implants, such as artificial joints. However, for their operation to be reliable, regular maintenance and verification of their accuracy is required. Especially with machines that work continuously and develop inaccuracies and wear much faster. Neglecting to maintain the machine can lead to a situation where the machine will have to be shut down and wait a long time for repair, which will cause financial losses in the company. During the regular inspection, it is possible to find out how great the inaccuracy of the machine is and thanks to that decide what work can be done on the given machine, or to schedule maintenance, when it will be convenient. This can be achieved with various measuring systems [1].

One of the most important features of CNC machine tools is their accuracy. The accuracy of production machines is evaluated as working and geometric accuracy. [2, 7]. Accuracy is given by the sum of mechanical and control system errors, which are minimal today. Today, standard CNC machines operate with an accuracy of $0.001 \mathrm{~mm}$ [2]. We evaluate the working accuracy on a standard product, which is manufactured under defined conditions. $[3,4]$. We evaluate the geometric accuracy without loading the machine. Here, the deviations of the paths of the individual movements of the machine parts are evaluated simultaneously with the deviations in the shape of important functional surfaces (eg the clamping surface of the table). [3] Every machine, whether new, overhauled or rebuilt, must be inspected for geometric accuracy. The inspection is performed during the output inspection as well as during operation

* Corresponding author: Robert Čep, E-mail address: robert.cep@vsb.cz 
during periodic inspections. It is most often performed according to international ISO standards, which are a prerequisite for the successful export of machines and their commissioning on the domestic, European and global markets. [3, 8]

If we want the machine to be reliable, able to produce portable parts in the required quality, in the long term, then in addition to regular maintenance, it is also necessary to regularly monitor changes in its accuracy. This is done by the following tests $[5,9]$ :

- measurement of vibrations of rotating devices;

- measuring the positioning accuracy of the machine;

- circular interpolation measurement;

- clamping force measurement;

Next, we will deal with the measurement of circular interpolation, specifically the measurement with the Renishaw Ballbar QC20-W.

\section{Renishaw Ballbar QC20-W System}

This calibration system is the easiest, fastest, and most effective way to monitor the condition of the machine tool $[7,8]$. It achieves this with a very precise linear encoder and a pair of spheres at both ends. Precise magnetic dishes are used in the measurement, one of which is fixed to the spindle (or casing) of the machine and the other to the worktable of the machine, between which the balls are placed cinematically [8,9]. Thanks to this, the system can measure even small changes in the radius of the programmed machine path. [6]. Technical parameters of system are in Table 1.

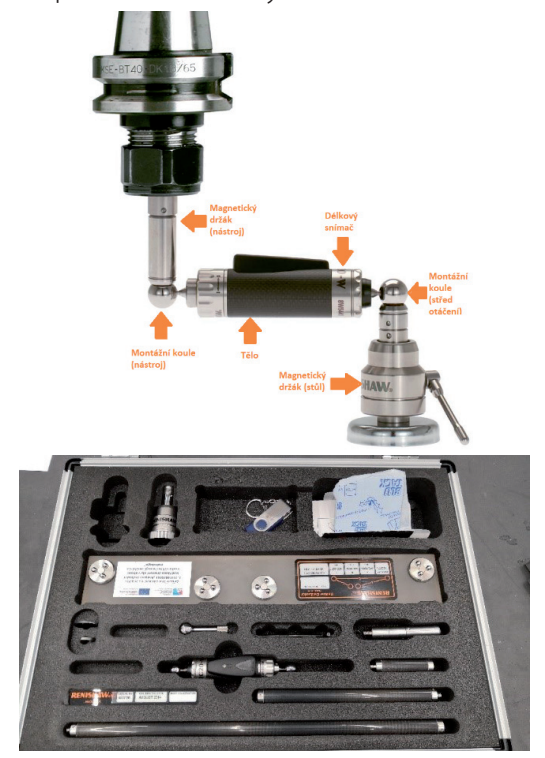

Figure 1: Renishaw Ballbar QC20-W System [6].
Table 1: Technical parameters of Ballbar QC20-W system [6].

\begin{tabular}{|l|l|l|}
\hline Parameter & $\mathrm{QC20}-\mathrm{W}$ & Unit \\
\hline Senzor resolution & 0,1 & $\mu \mathrm{m}$ \\
\hline Senzor accuracy & $\pm 0,5$ & $\mu \mathrm{m}$ \\
\hline Measuring systém accuracy & $\pm 1,25$ & $\mu \mathrm{m}$ \\
\hline Senzot measuring range & $\pm 1,0$ & $\mathrm{~mm}$ \\
\hline Maximal scanning speed & 1000 & $\mathrm{~Hz}$ \\
\hline Data transfer via Bluetooth & 10 & $\mathrm{~m}$ \\
\hline Operating temperature range & $0-40$ & ${ }^{\circ} \mathrm{C}$ \\
\hline
\end{tabular}

The Renishaw Ballbar QC20-W can diagnose 2 groups of errors. The first group of errors includes machine errors and the second measurement errors. [5]

Machine errors:

- Axial clearance

- Cyclic error

- Lateral clearance (deviation)

- Swapping management and controlled roles

- Reversing tips

- Scale error (mismatch)

- Servo mismatch

- Perpendicularity

- Jerky feed

- Machine vibration

- Trilobal graph - straightness

Measurement errors:

- Spiral error

- Deviation change

- Dashed graph

- Rotated graph

- Radius change

- Trilobal graph

\section{Measuring of DMG MORI DMU Machine Tool}

The measurements took place in new laboratories in the premises of VŠB-TUO CPIT TL1. A five-axis DMG MORI - DMU 50 CNC milling machine with a HEIDENHAIN iTNC 530 control system was used as the measuring machine.

The measurement took place in three levels, namely $X Y, Y Z$ and $Z X$. In each plane, 3 feed rates were measured, with each measurement taking place three times. The first was measured in the $X Y$ planes, from the lowest feed rate, which is $1000 \mathrm{~mm} /$ min, over $1500 \mathrm{~mm} / \mathrm{min}$ and finally $2000 \mathrm{~mm} / \mathrm{min}$. Then followed the same procedure in the $Y Z$ plane, and finally in the ZX plane. No temperature was measured on the machine during the measurement 
and the machine was tested after work.

NC programs for the planes have been created in the Ballbar 20 software and adapted for the HEIDENHAIN control system. Subsequently, they were loaded into the machine tool, where it was then sufficient to adjust the feed rate to the desired value. A holder with a magnetic bowl was clamped in the spindle of the machine and a magnetic holder with a magnetic bowl was placed on the work table approximately in the middle. Before each initial start of the program (when changing planes), an empty test was performed to verify its functionality and to prevent possible damage to the measuring device.

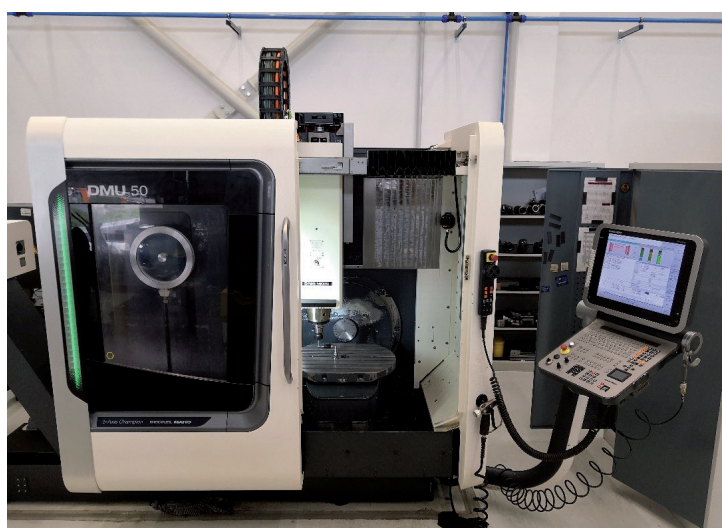

Figure 2: CNC milling DMG MORI DMU 50.

The ballbar was set to a length of $100 \mathrm{~mm}$, where it was calibrated in a Zerodur calibrator before each insertion into the machine, which specifically has a calibration of $100.0011 \mathrm{~mm}$. After calibration, it was attached to the magnetic bowls with its ends, the command to start testing was turned on in the software, and then the machine itself started.

After the measurement on the machine was completed, the measurement was evaluated in the Ballbar 20 system.

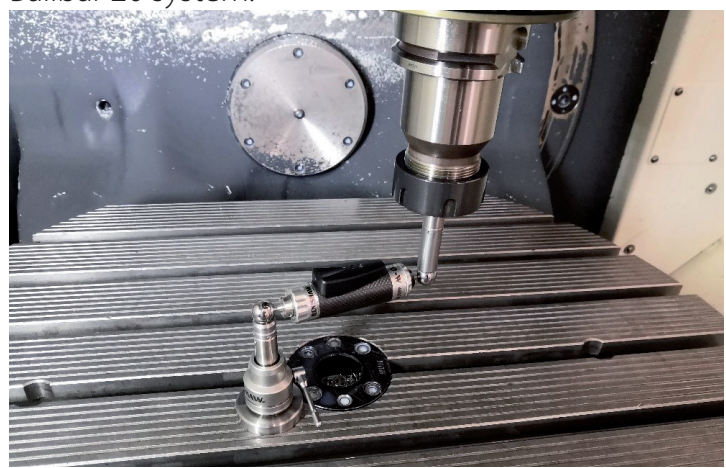

Figure 3: Renishaw Ballbar QC20-W system during measuring at $\mathrm{XY}$ plane.

\subsection{Measuring in XY plane}

In this plane, the measurement takes place along a $360^{\circ}$ path.

Table 2: Measured data in XY plane

\begin{tabular}{|l|l|l|l|}
\hline Feed speed $[\mathrm{mm} / \mathrm{min}]$ & 1000 & 1500 & 2000 \\
\hline Roundness deviation $[\mu \mathrm{m}]$ & 8,1 & 7 & 8,1 \\
\hline
\end{tabular}

In two of the three measurements, namely the first and third, the most servo delays in the $X$ and $Y$ axes were found to be the most percentage. In the second measurement, the most relative measurement errors were caused by non-run-in or run-over from one axis to another. The servo delay appeared less here.

At a feed rate of $1500 \mathrm{~mm} / \mathrm{min}$, the servo delay was most pronounced in all three cases, which is also caused by a reversal peak error. The error is most pronounced in the third measurement, where it is $23 \%$, and less in the other two.

At this speed (2000 mm/min), the servo delay also showed the most, which is up to $35 \%$ at the first measurement. So in the XY plane, the servo delay is really the biggest problem and is most pronounced at a feed rate of $2000 \mathrm{~mm} / \mathrm{min} .2 .2$

\subsection{Measuring in $\mathrm{YZ}$ plane}

In this plane, the measurement takes place along a $220^{\circ}$ path.

Table 3: Measured data in YZ plane.

\begin{tabular}{|l|l|l|l|}
\hline Feed speed $[\mathrm{mm} / \mathrm{min}]$ & 1000 & 1500 & 2000 \\
\hline Roundness deviation $[\mu \mathrm{m}]$ & 8,7 & 6,6 & 6,9 \\
\hline
\end{tabular}

In the first two measurements, the perpendicularity is most pronounced, which is up to $25 \%$. In all cases, the perpendicularity error is positive, which means that the angle between the two positive directions exceeds $90^{\circ}$. The cause can be wear of the machine guide, where play occurs when moving in the axes. The second largest crowd has a servo delay.

In all cases (fig. 8), the servo delay of up to $31 \%$ is most pronounced here. Furthermore, up to $30 \%$ perpendicularity is manifested. In the second and third measurements, the amplitude of the cyclic error then occurs up to $19 \%$, which can be caused by the uneven pitch of the ball screw thread.

When measuring at speed $2000 \mathrm{~mm} / \mathrm{min}$ ), a different error was most pronounced in each experiment. In the first, it was the amplitude of the cyclic error in both measured axes, where it was up to $23 \%$. In the second measurement, the 


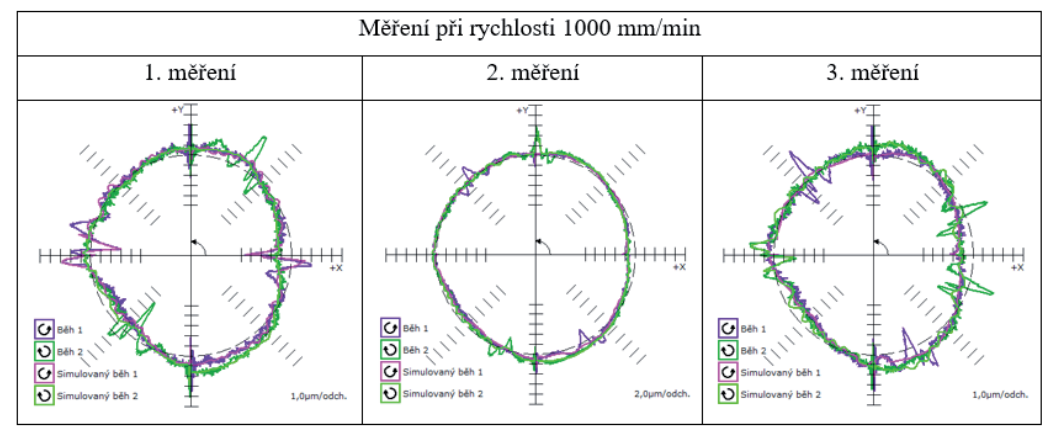

Figure 4: Measured graphs in XY plane at feed speed $1000 \mathrm{~mm} / \mathrm{min}$ (3 independent measuring).

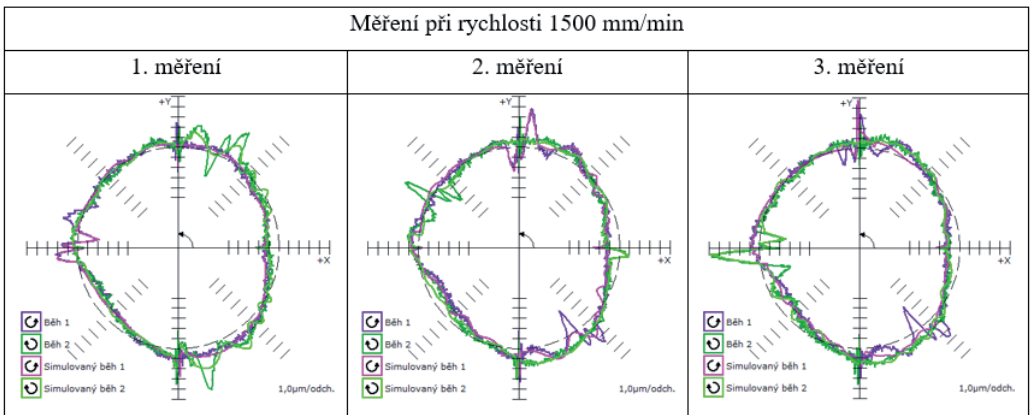

Figure 5: Measured graphs in XY plane at feed speed $1500 \mathrm{~mm} / \mathrm{min}$ (3 independent measuring).

\begin{tabular}{|c|c|c|}
\hline \multicolumn{3}{|c|}{ Měření při rychlosti $2000 \mathrm{~mm} / \mathrm{min}$} \\
\hline 1. měření & 2. měření & 3. měrení \\
\hline
\end{tabular}

Figure 6: Measured graphs in XY plane at feed speed $2000 \mathrm{~mm} / \mathrm{min}$ (3 independent measuring).

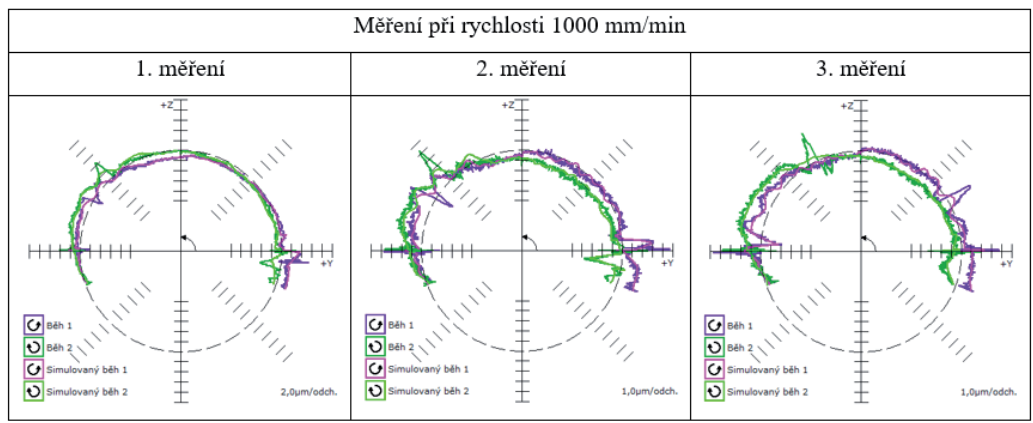

Figure 7: Measured graphs in YZ plane at feed speed $1000 \mathrm{~mm} / \mathrm{min}$ (3 independent measuring). 
delay of the servos with transverse play was most pronounced, where they are the main cause of play in the machine guide. In the third measurement, the perpendicularity was $26 \%$.

\subsection{Measuring in ZX plane}

In this plane, the measurement takes place along a $220^{\circ}$ path.

Table 4: Measured data in ZX plane

\begin{tabular}{|l|l|l|l|}
\hline Feed speed $[\mathrm{mm} / \mathrm{min}]$ & 1000 & 1500 & 2000 \\
\hline Roundness deviation $[\mu \mathrm{m}]$ & 5,9 & 4,7 & 4,6 \\
\hline
\end{tabular}

Perpendicularity was the most pronounced here, which was up to $34 \%$. There was also a servo delay of $16 \%$ and a lateral play of $14 \%$.

As with a feed rate of $1000 \mathrm{~mm} / \mathrm{min}$, the perpendicularity, which was up to $30 \%$, and then the servo delay were the most pronounced.

The amplitude of the cyclic error reached $30 \%$ in the second measurement, otherwise the perpendicularity was again most pronounced up to $35 \%$. Although the measurements were performed immediately after each other under the same conditions and the same procedures, the measurement graphs at a speed of 2000 mm / min in the ZX plane differ considerably.

\section{Evaluation of roundness deviation}

Circularity is the difference between the largest and smallest radii, which is recorded by the ballbar as the machine moves along the path of the data acquisition arc. The lower the value, the better the accuracy of the machine. [5]

The following table lists all the mean values of roundness, measured in individual planes at certain speeds.

Table 5: Table of resulting roundnesses

\begin{tabular}{|l|l|l|l|}
\hline Feed speed [mm/min] & 1000 & 1500 & 2000 \\
\hline Roundness deviation $[\mu \mathrm{m}] \mathrm{XY}$ & 8,1 & 7,0 & 8,1 \\
\hline Roundness deviation $[\mu \mathrm{m}] \mathrm{YZ}$ & 8,7 & 6,6 & 6,9 \\
\hline Roundness deviation $[\mu \mathrm{m}] \mathrm{ZX}$ & 5,9 & 4,7 & 4,6 \\
\hline
\end{tabular}

As shown in the following graph (Fig. 13), in the XY plane, with the addition of the feed rate, the roundness first decreased and then increased again to the original value. At the $Y Z$ plane, this condition also occurred, but not with such a renewed increase. In the ZX plane, the circularity manifested itself only by a decrease. It follows that, as shown in the following graph, the circularity is constant in the $X Y$ plane, so that the increase in speed has no effect on it. In the other two planes $Y Z$ and $Z X$, the

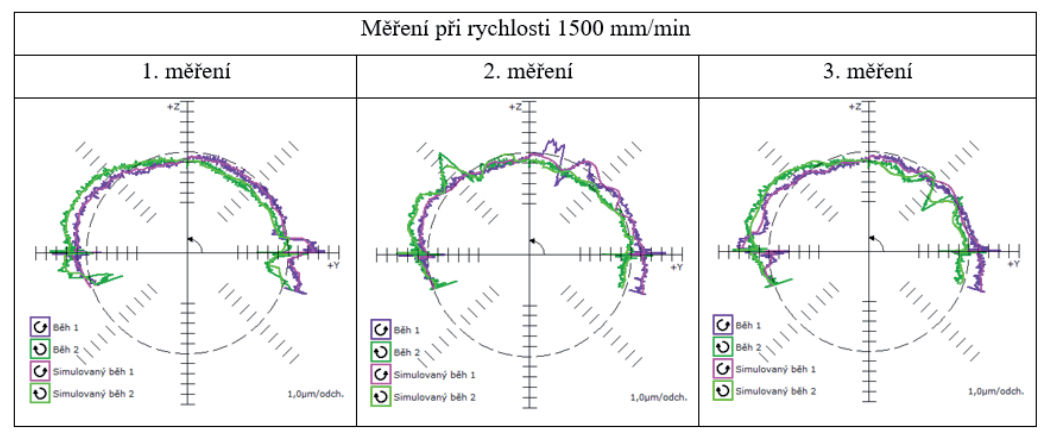

Figure 8: Measured graphs in YZ plane at feed speed $1500 \mathrm{~mm} / \mathrm{min}$ ( 3 independent measuring).

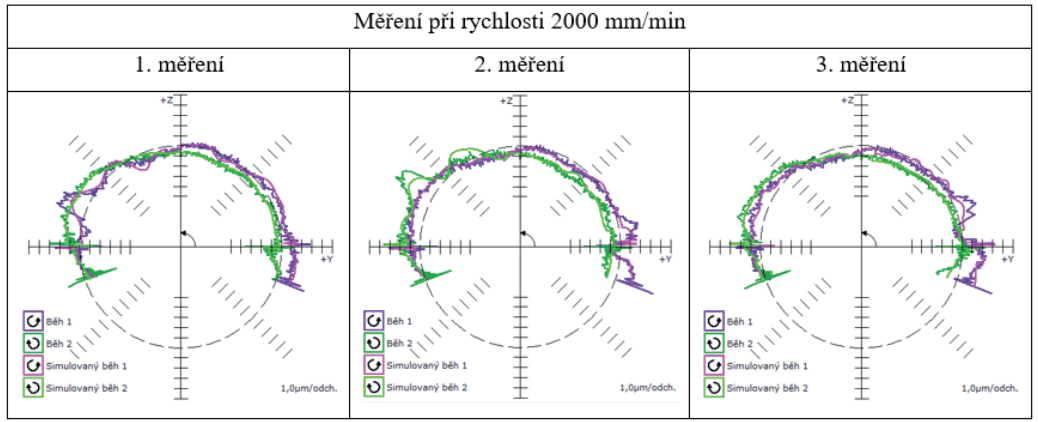

Figure 9: Measured graphs in YZ plane at feed speed $2000 \mathrm{~mm} / \mathrm{min}$ (3 independent measuring). 


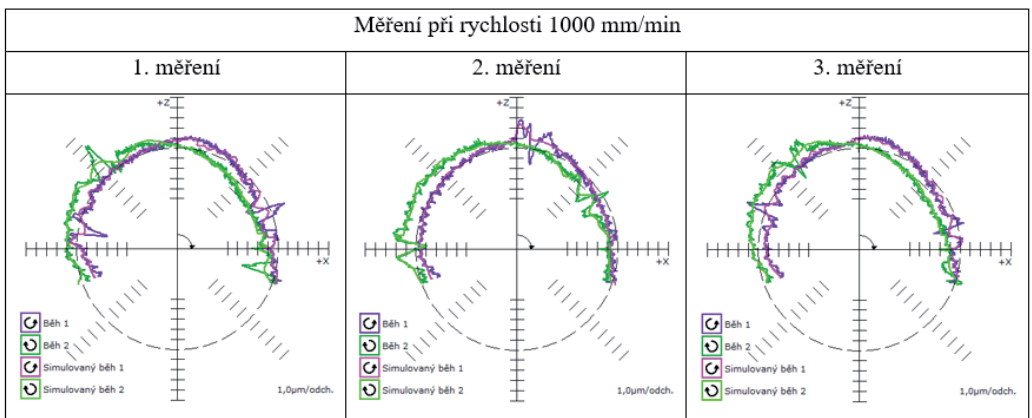

Figure 10: Measured graphs in ZX plane at feed speed $1000 \mathrm{~mm} / \mathrm{min}$ ( 3 independent measuring).

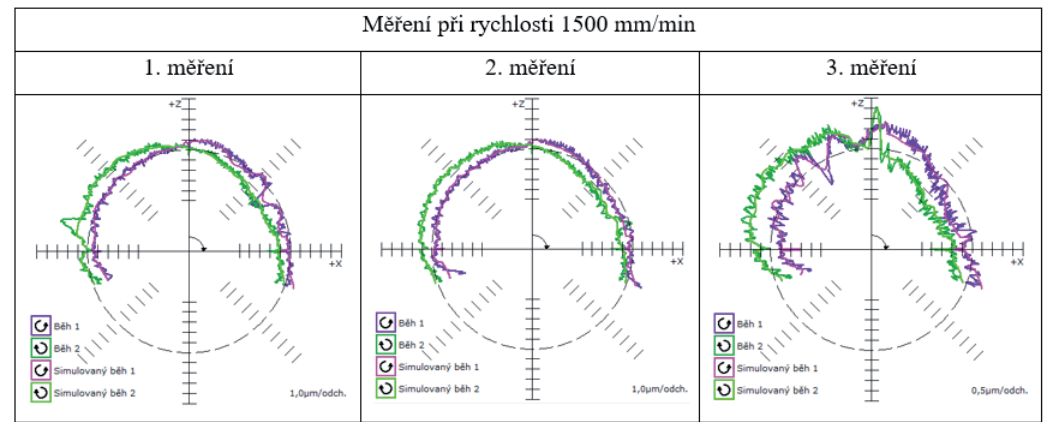

Figure 11: Measured graphs in ZX plane at feed speed $1500 \mathrm{~mm} / \mathrm{min}$ (3 independent measuring).

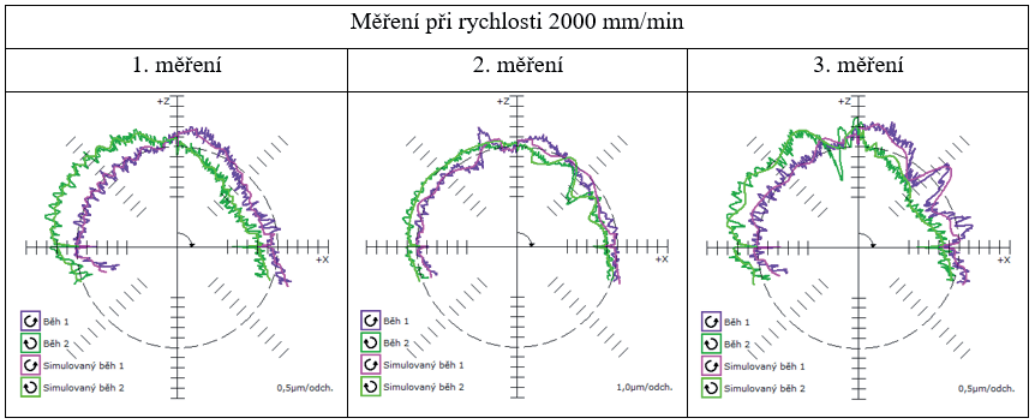

Figure 12: Measured graphs in ZX plane at feed speed $2000 \mathrm{~mm} / \mathrm{min}$ (3 independent measuring).

circularity manifested itself with a higher feed rate as decreasing.

Nevertheless, the $X Y$ plane is the least accurate, the YZ plane is a little more accurate, and the ZX plane is the most accurate. According to the determined values, it can be concluded (it can also be verified according to the volumetric diagnostics available to the Ballbar 20 software) that for production with lower accuracy, it is appropriate to use a speed of 2000 mm / min from our feed rates. However, if the production is more accurate, then it is best to use a feed rate of $1500 \mathrm{~mm} / \mathrm{min}$, which shows the smallest sphericity (the higher the value, the worse the parameters of the machine). The worst result

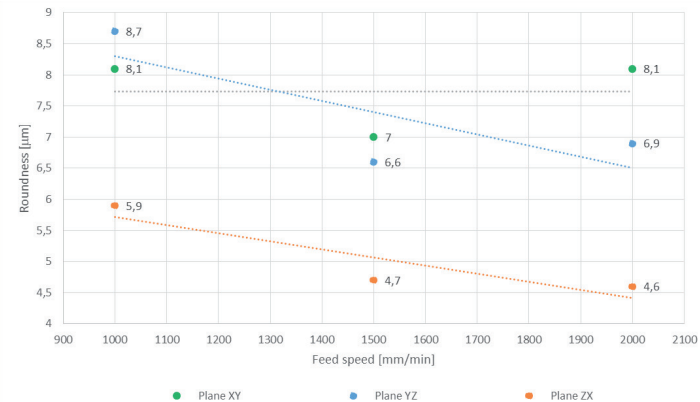

Figure 13: Graph of roundness comparison when changing the feed rate in individual planes. 
here is the lowest feed rate.

\section{Conclusions}

In this article, the accuracy of the DMG MORI DMU 50 CNC milling machine with the HEIDENHEIN iTNC 50 control system was measured. The Ballbar QC20-W system from Renishaw was used for this. The measurement took place in three levels. In the $X Y$ plane, the measurement took place along a $360^{\circ}$ path and in the $Y Z$ and $Z X$ planes along a $220^{\circ}$ path. The measurement range was set to a radius of $100 \mathrm{~mm}$, and the system was calibrated in the Zerodur calibrator to $100.0011 \mathrm{~mm}$ before each measurement. In each plane, measurements were made at feed rates of 1000, 1500 and 2000 $\mathrm{mm} / \mathrm{min}$, each measurement being performed three times. The results were then evaluated using tables and graphs. In the XY plane, the servo delay was the most pronounced, which is the error of the reversing tip machine, where there is a momentary stop instead of a smooth change of stroke at the turning point. Furthermore, there was a relative measuring error caused by a scaling error, which arises from the overrun or non-running of one axis to another. In the $Y Z$ plane, the perpendicularity of the machine was most pronounced, which can be caused by the bending of the axes locally, or by the overall unbalance of the machine, and therefore it is impossible to achieve perpendicularity when machining the end faces. Furthermore, the servo delay and the amplitude of the cyclic error manifested themselves. In the ZX plane, the previous errors were manifested again, namely the perpendicularity and the servo delay. When evaluating the roundness, it was shown that for two of the three axes, increasing the feed speed of the machine has a favorable effect on the roundness. In one case, the feed rate did not have much effect on the roundness. Despite all this, it turned out that of the speeds we measured, the most ideal feed for this machine is $1500 \mathrm{~mm} / \mathrm{min}$ and the worst $1000 \mathrm{~mm} /$ $\mathrm{min}$. From this it can be determined that a speed of $2000 \mathrm{~mm} / \mathrm{min}$ can be used for less precise work and $1500 \mathrm{~mm}$ / min for more precise work. Nevertheless, I would recommend re-measuring the machine over several repetitions to obtain a more accurate mean value and then trying to eliminate the causes of the problems found so that any displacements can be used, regardless of the manufacturing accuracy. I would also recommend regular inspection and maintenance of the machine.

\section{References and Notes}

1. LIŠKA, Radim. Měření přesnosti obráběcího stroje : bakalářská práce. Ostrava, 2020, 55 s.

2. BUMBÁLEK, Leoš. Kontrola a měření: pro SPŠ strojní. Praha: Informatorium, 2009. ISBN 978-80-7333-072-9.

3. SVOBODA, Rostislav. Přesnost CNC stroje? Dnes dokáže pracovat i na nanometry. Factory Automation [online]. [cit. 2020-04-21]. Dostupné z: https://factoryautomation. cz/presnost-cnc-stroje-dnes-dokaze-pracovat-i-nananometry/

4. KRATOCHVÍL, Pavel. Údržba obráběcích strojů. MM spektrum [online]. [cit. 2020-04-19]. Dostupné z: https:// www.mmspektrum.com/clanek/udrzba-obrabecich-stroju. html

5. Systém ballbar QC20-W. Reinshaw [online]. [cit. 2020-0420]. Dostupné Z: https://www.renishaw.cz/cs/systemballbar-qc20-w--11075

6. Software Ballbar 20 - User Guide

7. Kuric, Ivan; Tlach Vladimír; Cisar Miroslav; Sagova Zuzana; Zajacko, Ivan. Examination of industrial robot performance parameters utilizing machine tool diagnostic methods. INTERNATIONAL JOURNAL OF ADVANCED ROBOTIC SYSTEMS, 2020, Vol. 17, No. 1. ISSN 1729-8814. DOl: $10.1177 / 1729881420905723$

8. Tlach, Vladimir, Sagova, Zuzana; Kuric, Ivan. Circular and quasi-circular paths for the industrial robots measuring with the Renishaw Ballbar QC20-W. In XXIII POLISH-SLOVAK SCIENTIFIC CONFERENCE ON MACHINE MODELLING AND SIMULATIONS (MMS 2018), Vol. 254. ISSN 2261-236X. DOI: 10.1051/matecconf/201925405007

9. Holub, Michal; Bradac, Frantisek; Pokorny, Zdenek; Jelinek, Adam. APPLICATION OF A BALLBAR FORDIAGNOSTICS OF CNC MACHINE TOOLS. MM SCIENCE JOURNAL, 2018, Vol 2018, pp. 2601-2605. ISSN 1803-1269. DOI: 10.17973/ MMSJ.2018_12_2018032 